\title{
Analysis of the cues used by patients when making assessments of their asthma severity
}

\author{
E.A. Barley and P.W. Jones
}

ABSTRACT: This study measured the relative contribution of four cues: symptoms, effect on activities, emotions and social life, to patients' judgments of overall asthma severity.

Judgement analysis techniques were applied to patients' assessments of overall asthma severity using asthma states described in scenarios based on these cues.

Altogether, 40 patients, mean age 52 yrs, mean forced expiratory volume in one second $67 \%$ predicted, were studied. The relative importance of the cues varied widely between patients; symptoms contributed to $47 \%$ of the judgment of asthma severity (range 15-86\%), activities $19 \%$ $(1-73 \%)$, emotions $14 \%(0-43 \%)$, and social life $19 \%(2-57 \%)$. Some patients had difficulty with the judgment task, they tended to be older or have worse health. A total of 21 patients had consistent judgment policies. Cluster analysis identified two policy types. In one, symptoms were weighted heavily, in the other all cues were weighted similarly. Policies were not related to disease or demographic factors.

Symptoms are important cues for patients when assessing asthma severity, but other cues may be more important in some patients. Patients fall into two groups: those who rely on symptoms and those who use several cues.

KEYWORDS: Asthma, health status

imple global estimates, such as "How severe is your asthma today?", are used widely in routine practice and clinical research to measure patients' perception of their asthma severity. Despite the ubiquity of such estimates, it is not known which factors patients take into consideration when making them. However, there is a large body of work that has been carried out in the development of asthmaspecific health status questionnaires to identify those aspects of the disease that are common and important to patients. The most detailed and established asthma-specific health status questionnaires are: the Asthma Quality of Life Questionnaire (AQLQ) [1], the St George's Respiratory Questionnaire (SGRQ) [2], the AQLQ [3] and the Living with Asthma Questionnaire (LWAQ) [4]. Examination of these questionnaires shows that their items, or the components into which related items are grouped, fall into four broad domains: asthma symptoms and the impact of asthma on daily activities, emotions and social life. These are similar to the domains described as common to most generic health-status questionnaires [5].
This study describes the use of judgement analysis (JA) techniques to explore the factors that patients take into account when making judgments as to their overall asthma severity. JA has been used to determine judgment policies used by clinicians when making clinical decisions [6-8]. It has also been used in patients to measure individual quality of life [9-11]. Judgment policies derived using these methods have been shown to relate well to actual decision-making $[12,13]$. Furthermore, they have been shown to predict actual behaviour better than individuals' stated policies, i.e. the policy they say that they use $[14,15]$. We have used these techniques to address the following questions: 1) do patients use consistent judgment policies when assessing their asthma severity?; 2) which of the four main health status domains are most important to patients in assessing their asthma severity?; and 3) which factors influence patients when making judgments about the severity of their asthma?

\section{METHODS}

Participants

Patients with a clinical diagnosis of asthma made by a consultant chest physician were recruited

\section{AFFILIATIONS}

Division of Physiological Medicine, St George's Hospital Medical School, London, UK

\section{CORRESPONDENCE}

\section{P.W. Jones}

Division of Physiological Medicine St George's Hospital Medical School Cranmer Terrace

Tooting

London, SW17 ORE

UK

Fax: 442087255955

E-mail: pjones@sghms.ac.uk

Received:

July 072004

Accepted after revision:

November 302004 
from two outpatient clinics. All patients attending the clinic on the day the author (E. Barley) was present were approached. A total of 40 patients (female $=25$ ) aged $27-82$ yrs (mean 52 yrs) agreed to participate. The mean number of years since diagnosis was $25 \pm 18$ yrs or $53 \pm 37 \%$ of their life. The mean post-bronchodilator forced expiratory volume in one second (FEV1) was $67.4 \pm 25.7 \%$ predicted. All were prescribed a $\beta_{2^{-}}$ agonist and an inhaled steroid. Nine were also prescribed other asthma medication, such as a xanthine, an anticholinergic or a cromone and six were currently taking oral steroids. Seventeen patients had never smoked, five were current and 18 were ex-smokers. All had been given asthma education and self-management training. Patients with other inter-current disease or a history of psychiatric illness were excluded. Patients were divided into two groups according to their medication regimen; simple: $\beta_{2}$-agonist plus an inhaled steroid; complex: $\beta_{2}$-agonist and inhaled steroid plus xanthine, anticholinergic, cromone or oral steroid. Ethical approval for the study was provided by Wandsworth Health Authority Local Research Ethics Committee, London, UK. Written consent was obtained from all patients.

\section{Judgement analysis}

In JA, participants make judgments about a set of hypothetical cases, which are described in terms of the factors or cues under study. The cues tested were the four main asthma health status domains: symptoms, activity, emotions and social. Each hypothetical case was characterised in terms of the impact of asthma on each of these domains. Symptoms were described in terms of wheeze, cough and breathlessness; emotions were defined in terms of anxiety, as this is the principle negative emotion associated with asthma [16]; disturbance to daily activity and to social life were undefined. Each cue was presented at one of four levels of severity. Cues and levels are shown in Appendix 1. Four cues with four levels would produce 256 cases $(4 \times 4 \times 4 \times 4)$. Specialist JA software Policy PC [17] was used to randomly generate 50 cases. This is the number that can be comfortably judged by participants and is sufficient for robust analysis [18]. Unknown to the patients, ten replicated cases were included to allow a test of within-patient reliability. An example of a case, in the form presented to the patients, is shown in Appendix 2. Patients made judgments about overall asthma severity of each of the 60 cases using a visual analogue scale (VAS).

\section{Other measurements}

\section{Current asthma severity}

Each patient's current global asthma severity was measured by asking patients to mark a $10 \mathrm{~cm}$ VAS labelled at either end "no asthma" or "extremely severe" in response to the question: "How severe do you consider your asthma to be?"

\section{Health status}

Health status was measured using SGRQ [2]. Scores are computed to range $0-100(0=$ best health).

\section{Mood}

Mood was measured using the Hospital Anxiety and Depression Scale (HAD) [19]. Scores for each range 0-21 ( $0=$ best mood).

\section{Lung function}

FEV1 was measured $20 \mathrm{~min}$ following bronchodilator use. Patients took two puffs of Salbutamol (100 mg per actuation) using their usual method. The best of three attempts was recorded. Spirometry data were expressed as a percentage of the predicted value [20].

\section{Study design}

Patients were interviewed at home. Age, height, self-reported number of years with a diagnosis of asthma (disease duration), medication regimen and smoking history were recorded. Spirometry was performed. The patients also completed the judgment task, the current asthma severity rating, the SGRQ and the HAD. The order of presentation was randomised using a Latin square. Interviews lasted $\sim 1 \mathrm{~h}$.

\section{Analysis}

Within-patient reliability was assessed using the correlation between judgments of the 10 pairs of replicated cases. In JA studies, a Pearson's $\mathrm{r}$ of 0.6 is considered to reflect an acceptable level of reliability [18], so patients were categorised into reliable $(r \geqslant 0.6)$ and less reliable $(r<0.6)$ groups.

Judgment data were analysed using the multiple regression method developed by HAMMOND and AdELMAN [21]. For each patient, multiple regression, with the rating of asthma severity as the dependent variable and the cue values as the independent variables, was determined. The coefficient $R^{2}$ represents the proportion of the variance in the judgments that can be accounted for by the derived weights [22]. It also reflects the consistency of each patient's judgments; $R^{2}=1$ would indicate that the patient always gave each cue the same importance when rating overall severity, and that the overall judgment was completely accounted for in terms of the cues and weights attributed to them [23].

The JA-derived weights for the cues were used as measurements of how much each had contributed to the judgment. Relative weights were reported. These add up to 100 and may be interpreted as if the patient had divided up 100 points among the cues in proportion to the amount of emphasis they placed on the cue when making their overall judgments about asthma severity [24]. These weights are not independent of each other for the purposes of statistical analysis because the size of one affects the size of the other three.

The influence of demographic and asthma-related factors on the JA-derived policies was tested by performing multinomial logistic regression, with the rank-ordered weights for each cue as the dependent variable. Rank ordering was necessary to overcome the problem of cue weight interdependence. A separate regression was calculated for each variable because some of the independent variables were correlated. The significance of a covariate was tested using a logistic likelihood ratio test (Chi-squared test).

To identify groups of patients whose cue weighting policies were most similar, a cluster analysis was performed. Only those patients who were reliable in the judgment task were analysed. Cue weights were converted to standard (z) scores before clustering them; this ensured that cue weights having the greatest variability across patients did not dominate the clustering process [24]. A hierarchical cluster analysis 
using Ward's minimum variance method [25] was carried out. Patients within different clusters were compared for differences on the asthma-related variables. Results are presented as mean $\pm \mathrm{SD}$, unless otherwise indicated.

\section{RESULTS}

\section{Data collection}

JA data were available for all patients, but in one patient no regression weights could be produced. On examination of this patient's data, it was apparent that they had marked the centre point of each VAS irrespective of cue level; this patient was excluded from further analysis. Questionnaire and rating data were available for all patients, with no missing answers. Postbronchodilator FEV1 data were available for 35 patients, as five were unwilling to take medication for the purposes of the study.

\section{Patient details}

Mean SGRQ total score was $40.6 \pm 17.7$. Mean HAD score was $7 \pm 5$ for anxiety and $4 \pm 3$ for depression. Median global asthma severity score was 3.5 (range 0.2-10). Mean FEV1 was $67.4 \pm 25.7 \%$ pred

\section{Reliability}

Correlations between replicated cases ranged from $r=0.02$ to $\mathrm{r}=0.94$ (median $\mathrm{r}=0.60$ ). In total, 21 patients were found to be reliable (i.e. $r \geqslant 0.6$ ). In these patients, correlations ranged 0.60 0.94 (median=0.82). Internal consistency measured as $\mathrm{R}^{2}$ ranged 0-0.94 (median $R^{2}=0.62$ ) for the entire sample, and 0.18-0.94 (median $\mathrm{R}^{2}=0.77$ ) for the subgroup of 21 reliable patients. The estimates for $r$ and $R^{2}$ were correlated $(r=0.69$, $p<0.0001)$. The scores for the asthma-related variables of reliable and less reliable patients are shown in table 1 . The less reliable patients were older, reported worse health and were prescribed more medication.

\section{Judgment policies}

The importance placed on each cue varied widely between patients (table 2). Findings were similar for reliable and less

\begin{tabular}{lccc} 
TABLE 1 & $\begin{array}{l}\text { Comparison of the scores of reliable and less } \\
\text { reliable patients on the demographic and } \\
\text { health-related variables }\end{array}$ \\
& Reliable $^{\#}$ & Less reliable & p-value \\
\hline Age yrs & 46.2 & 56.4 & 0.04 \\
Sex M/F & $10 / 11$ & $5 / 13$ & NS \\
FEV 1 & 72.7 & 62.8 & NS \\
Disease duration & 63.1 & 44.7 & NS \\
SGRQ total score & 34.1 & 48.2 & 0.01 \\
Global asthma & 2.7 & 4.3 & 0.04 \\
Anxiety & 7.3 & 6.4 & NS \\
Depression & 2.7 & 4.5 & NS \\
Medication regimen & $19 / 2$ & $8 / 10$ & 0.002 \\
simple/complex & & & \\
\hline
\end{tabular}

M: male; F: female; FEV1: forced expiratory volume in one second; SGRQ: St George's Respiratory Questionnaire; NS: nonsignificant. \#: Pearson's r between ratings of replicated cases $\geqslant 6$

\begin{tabular}{|c|c|c|c|c|c|}
\hline TABLE 2 & $\begin{array}{l}\text { yement ar } \\
\text { ortance of } \\
\text { al asthma }\end{array}$ & $\begin{array}{l}\text { ysis-c } \\
\text { des to } \\
\text { everit }\end{array}$ & $\begin{array}{l}\text { ived we } \\
\text { atients' }\end{array}$ & $\begin{array}{l}\text { hts an } \\
\text { Idgme }\end{array}$ & $\begin{array}{l}\text { the } \\
\text { s of }\end{array}$ \\
\hline \multirow[t]{2}{*}{ Cue } & \multirow[t]{2}{*}{ Weight $^{\#}$} & \multicolumn{4}{|c|}{ Patients ranking the cue as: } \\
\hline & & First & Second & Third & Fourth \\
\hline \multicolumn{6}{|l|}{ Symptoms } \\
\hline Less reliable & $39(18-70)$ & 11 & 3 & 4 & 0 \\
\hline Reliable" & $54(15-86)$ & 14 & 6 & 1 & 0 \\
\hline \multicolumn{6}{|l|}{ Activity } \\
\hline Less reliable & $20(1-34)$ & 1 & 10 & 4 & 3 \\
\hline Reliable" & $18(6-73)$ & 3 & 5 & 9 & 4 \\
\hline \multicolumn{6}{|l|}{ Emotions } \\
\hline Less reliable & $18(2-43)$ & 4 & 3 & 4 & 7 \\
\hline Reliable & $11(0-31)$ & 1 & 3 & 8 & 9 \\
\hline \multicolumn{6}{|l|}{ Social } \\
\hline Less reliable & $22(3-49)$ & 2 & 4 & 7 & 5 \\
\hline Reliable & $17(2-57)$ & 3 & 9 & 6 & 3 \\
\hline
\end{tabular}

Data are presented as mean (range) or $\mathrm{n}$. Rank ordering of cues was performed using weights elicited by judgment analysis. There were no significant differences (Chi-squared test $p>0.05$ ) in the mean weight or the ranking of weights between the two groups of patients (less reliable patients $n=18$, reliable patients $\mathrm{n}=21$ ). ${ }^{\#}$ : out of $100 ;{ }^{\circ}$ : judgments of replicated cases $r \geqslant 0.6$.

reliable patients. Overall, the mean weight was greatest for the symptoms cue. The cue with the lowest mean weight was emotions. The symptoms cue was ranked most often as the most important cue ( $64 \%$ of all patients); no patient ranked it as least important. The cue most often ranked least important was emotions (41\% of all patients).

\section{Influence of asthma-related variables on cue weights}

These analyses were performed using the 21 reliable patients only. A rank order relationship between each cue and a range of demographic and disease factors was tested for. Logistic regression showed that for the symptoms, activity and social cues there was a significant association between cue rank and disease duration (table 3), but there was little evidence of ordering in this association. The strongest association was between the symptoms cue and disease duration. Patients who placed symptoms as their first rank cue had had the disease for $77 \%$ of their life, compared with those for whom it was second in importance, who had had asthma for $27 \%$ of their life. There was also a weak association between the emotions cue and HAD score $(p=0.05)$. Rank ordering of cues was not associated with lung function (fig. $1 ; \mathrm{p}>0.05$ ).

\section{Cluster analysis}

Analysis of the 21 reliable patients indicated that they could be grouped according to two broad policy types (fig. 2). Further analysis showed that patients in the first cluster placed considerably more weight on symptoms than on any other cue, with the other cues weighted similarly. Patients in the second cluster tended to weight all cues similarly. Compared with patients in the first cluster, patients in the second cluster gave significantly more weight to all the cues, except symptoms (fig. 3). 


\begin{tabular}{|c|c|c|c|c|}
\hline \multirow{2}{*}{$\begin{array}{l}\text { TABLE } 3 \\
\text { Cue rank }\end{array}$} & \multicolumn{4}{|c|}{$\begin{array}{l}\text { Relationship, in reliable patients, between disease } \\
\text { duration and the importance of cues to overall } \\
\text { asthma severity }\end{array}$} \\
\hline & $\begin{array}{c}\text { Symptoms } \\
\text { cue }^{\#}\end{array}$ & $\begin{array}{l}\text { Activity } \\
\text { cue }\end{array}$ & $\begin{array}{c}\text { Emotions } \\
\text { cue NS }\end{array}$ & $\begin{array}{l}\text { Social } \\
\text { cue }^{+}\end{array}$ \\
\hline First & $\begin{array}{c}76.8 \pm 30.3 \\
14\end{array}$ & $\begin{array}{c}54.6 \pm 28.6 \\
3\end{array}$ & $\begin{array}{c}33.9 \\
1\end{array}$ & $\begin{array}{c}16.9 \pm 15.2 \\
3\end{array}$ \\
\hline Second & $\begin{array}{c}27.1 \pm 16.1 \\
6\end{array}$ & $\begin{array}{c}72.8 \pm 38.8 \\
5\end{array}$ & $\begin{array}{c}74.2 \pm 17.3 \\
3\end{array}$ & $\begin{array}{c}80.8 \pm 27.2 \\
8\end{array}$ \\
\hline Third & $\begin{array}{c}85.7 \\
1\end{array}$ & $\begin{array}{c}47.1 \pm 34.9 \\
9\end{array}$ & $\begin{array}{c}81.3 \pm 30.8 \\
8\end{array}$ & $\begin{array}{c}57.0 \pm 35.4 \\
6\end{array}$ \\
\hline Fourth & 0 & $\begin{array}{c}93.1 \pm 6.4 \\
4\end{array}$ & $\begin{array}{c}46.4 \pm 36.2 \\
9\end{array}$ & $\begin{array}{c}71.2 \pm 30.8 \\
4\end{array}$ \\
\hline $\begin{array}{l}\text { Data are pres } \\
\text { percentage of } \\
\text { cue's weight } \\
\text { replicated cas } \\
p=0.02 \text {. }\end{array}$ & $\begin{array}{l}\text { nted as mean } \\
\text { fe spent diagnc } \\
\text { relation to the } \\
r \geqslant 0.6 ; n=2\end{array}$ & $\begin{array}{l}\text { D or } n \text {. Diseas } \\
\text { ed as asthmati } \\
\text { eights of the } \\
\text { NS: nonsignific }\end{array}$ & $\begin{array}{l}\text { duration is ex } \\
\text { Cue rank is th } \\
\text { ner three cues } \\
\text { tt. }{ }^{\#:} p=0.00\end{array}$ & $\begin{array}{l}\text { essed as the } \\
\text { ank order of a } \\
\text { Judgments of } \\
?: p=0.05 \text {; }\end{array}$ \\
\hline
\end{tabular}

The policies of patients in the first cluster were more similar than the policies of those in the second cluster (fig. 2). Patients in the first cluster were slightly more reliable in their performance of the judgment task (Pearson's $r$ between replicated cases median $=0.90$, interquartile range (IQR) 0.08) than the patients in the second cluster (Pearson's $r$ between replicated cases median $=0.78$, IQR 0.19, Mann-Whitney U-test $\mathrm{p}=0.0012$ ). More of the variance in judgments was explained by the policies of the first cluster of patients (median $\mathrm{R}^{2}=0.88$, $\mathrm{IQR}=0.07$ ) than those of the second cluster (median $\mathrm{R}^{2}=0.64$, $\mathrm{IQR}=0.25$, Mann-Whitney U-test, $\mathrm{p}=0.003$ ). The two clusters did not differ on any demographic or disease-related variable.

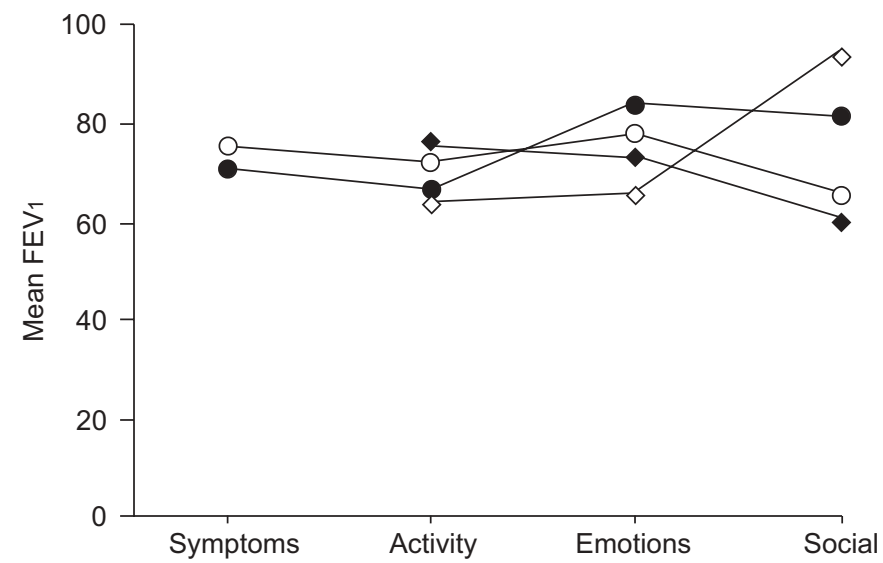

FIGURE 1. Association between forced expiratory volume in one second (FEV1) and cue importance. Lines represent patients ranking each cue as: most important (•; $n=$ symptoms 14 , activity 3 , emotions 1 , social 3 ); second most important $(O ; n=$ symptoms 6 , activity 5 , emotions 2 , social 8$)$; third most important $(\diamond ; n=$ symptoms 0 , activity 9 , emotions 6 , social 5$)$; and least important $(\diamond$; $\mathrm{n}=$ symptoms 0 , activity 4 , emotions 9 , social 3 ). One patient rated symptoms as third most important, but did not perform FEV1. Five patients gave two cues joint ranks, findings were similar whichever cue was used in the analysis. None of the associations were significant $(p>0.05)$.

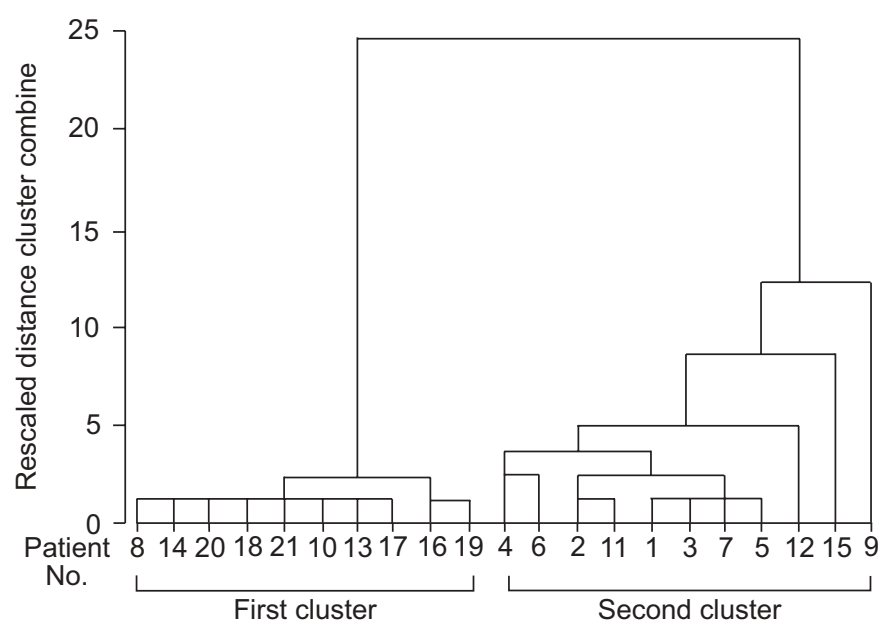

FIGURE 2. Dendrogram resulting from the cluster analysis of the 21 reliable patients to test whether patients fell into groups in terms of the relative importance to them of the four cues.

\section{DISCUSSION}

There was considerable variation between patients in terms of the importance placed on different domains of health when making judgments about overall asthma severity. Most considered that all four domains were of some importance, but asthma symptoms were used more frequently than any other domain. Restricted physical activity and social life due to asthma were the next most important and were given equal weight. Asthma-related anxiety was seen as being the least important. However, there was a great deal of individual variation. When the cues were rank-ordered to adjust for the nonindependence of cue weights, symptoms was the most important cue for only $64 \%$ of the group. Furthermore, whilst the emotions cue had the lowest mean weight, five patients considered it the most important. Nevertheless, all patients, except one who gave zero weight to emotions, used all of the cues when making the judgments. The current authors conclude that patients' perception of asthma severity is influenced by more than just the level of their asthma symptoms.

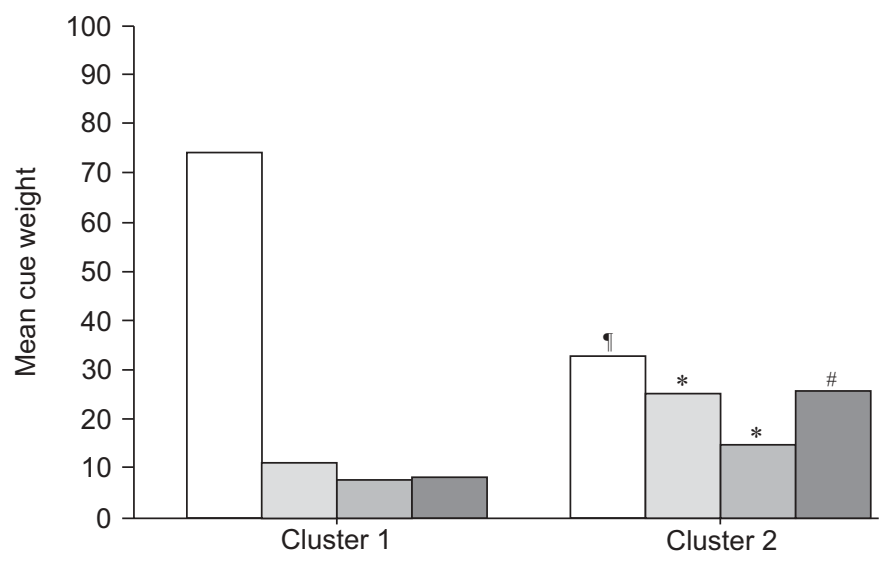

FIGURE 3. Mean cue scores for the two policy clusters found among the reliable patients. $\square$ : symptoms; $\square$ : activity; $\square$ : emotions; $\square$ : social. Difference between clusters: *: $p<0.05$; ${ }^{*}: p<0.001 ;{ }^{\natural}: p<0.0001 . n=10$ (cluster 1 ); $n=11$ (cluster 2). 
Cluster analysis identified two distinct policy types employed by patients. One policy placed most weight on symptom level, the other distributed the weight more evenly between cues. Little evidence that disease or demographic factors were associated with the chosen policy or choice of cue was found. There were significant associations between the relative importance of cues and disease duration (symptoms, activity and social cues) and HAD score (emotions cue), but no other factors were found to be associated with the patients' cue weightings. These observations are important because they suggest that a patient's choice of cues is not readily predictable from measurements made commonly in asthma, whether routinely or in a research setting. However, these subanalyses may have been limited by the small sample size in some of the subgroups. The use of JA data increases the power of an analysis, since each piece of data is based on many observations [24], nevertheless, further research is required to rule out any relationship between disease or demographic factors and cue use. It is also worth noting that the reliability of policies based on multiple cues was lower than those based on symptoms. The most likely explanation for this is that patients who rely on symptoms always rely upon them, whereas patients who take more factors into account may shift their relative importance between clinical states.

The within-patient reliability found in this study was comparable to that found in other studies using JA in patients [10]. The range of scores for replicated judgments indicated that several patients found the task difficult. Those patients were generally older and had worse asthma when assessed in a number of ways. These findings are supported by previous reports that elderly and cognitively impaired patients were less able to successfully complete a JA-based quality-of-life questionnaire (the SEIQoL) [26, 27].

The current authors have shown previously that differences in the wording of global scales (e.g. between level of asthma symptoms and level of effect on daily life) can influence patients' responses [28]. This study goes further and shows that such global estimates of asthma severity are influenced by hidden factors. These findings have important implications for research and clinical practice. These types of scales have often been used as a criterion of asthma severity against which other asthma measures have been validated. Asthma diary cards using global scales are used widely in clinical trials and symptom-free days are commonly used as important outcomes in such studies. There are also important implications for clinical practice. Asthma self-management plans form a central component of asthma care, since they have been shown to reduce admissions and unscheduled visits [29]. Self-management plans can be based upon symptoms and/or peak flow measurements, but in routine practice most patients probably revert to a symptom-based approach for much of the time. It is possible that optimum control can only be achieved if the education programme is based upon an understanding of the patients' cue preference. This study has not identified any method of predicting which cues will be used. Further work is needed to identify which cues patients use in practice (as opposed to the ones they say that they use) and to establish which judgment policies produce the best asthma control. It will also be important to establish the direction of causality in the current authors' observation that patients with worse asthma were less able to produce reliable policies. This may have been due to the complexity of the task, but an alternative hypothesis is that failure to develop a coherent approach to judging the severity of asthma leads to poor asthma control.

\section{APPENDIX 1. CUES AND CUE LEVELS AS THEY WERE DESCRIBED IN THE HYPOTHETICAL CASES}

Symptoms I am wheezy, breathless or coughing all the time I am wheezy, breathless or coughing a lot of the time

I am occasionally wheezy, breathless or coughing I am not wheezy, breathless or coughing at all

Activity My daily activities are severely restricted My daily activities are moderately restricted My daily activities are slightly restricted My daily activities are not restricted at all

Emotion I feel extremely anxious

I feel moderately anxious I feel slightly anxious I do not feel anxious

Social My social life is severely affected My social life is moderately affected My social life is slightly affected My social life is not affected at all

\section{APPENDIX 2. EXAMPLE OF A CASE}

Today, because of my asthma.

I am wheezy, breathless or coughing a lot of the time My daily activities are severely restricted

I do not feel anxious

My social life is moderately affected

If this were you, how severe would you consider your asthma to be? Please indicate by marking the line.

No asthma — Extremely severe asthma

(In the study the visual analogue scale was $10 \mathrm{~cm}$ in length).

\section{REFERENCES}

1 Juniper EF, Guyatt GH, Epstein RS, Ferrie PJ, Jaeschke R, Hillier TK. Evaluation of impairment of health related quality of life in asthma: development of a questionnaire for use in clinical trials. Thorax 1992; 47: 76-83.

2 Jones PW, Quirk FH, Baveystock CM, Littlejohns P. A selfcomplete measure of health status for chronic airflow limitation. Am Rev Respir Dis 1992; 145: 1321-1327.

3 Marks GB, Dunn SM, Woolcock AJ. A scale for the measurement of quality of life in adults with asthma. J Clin Epidemiol 1992; 45: 461-472.

4 Hyland ME. The living with asthma questionnaire. Respir Med 1991; 85: Suppl. B, 13-16.

5 Schipper H, Clinch JJ, Olweny CLM. Quality of life studies: definitions and conceptual issues. In: Spilker B, ed. Quality of life and pharmacoeconomics in clinical trials. Philadephia, Lippincott-Raven Publishers, 1996; pp. 11-23. 
6 Pfister M, Jakob S, Frey FJ, Neiderer U, Schmidt M, Marti HP. Judgment analysis is clinical nephrology. Am J Kidney Dis 1999; 34: 569-575.

7 Murray S, Del Mar C, O'Rourke P. Predictors of an antibiotic prescription by GPs for respiratory tract infections: a pilot. Fam Pract 2000; 17: 386-388.

8 Skaner Y, Bring J, Ullman B, Strender L-E. The use of clinical information in diagnosing chronic heart failure: a comparison between general practitioners, cardiologists and students. J Clin Epidemiol 2000; 53: 1081-1088.

9 O'Boyle C, McGee H, Hickey A, O'Malley K, Joyce CRB. Individual quality of life in patients undergoing hip replacement. Lancet 1992; 339: 1088-1091.

10 McGee H, O’Boyle C, Hickey A, O'Malley K, Joyce CRB. Assessing the QoL of the individual: the SEIQoL with a healthy and a gastroenterology unit population. Psychol Med 1991; 21: 749-759.

11 O'Boyle CA. The schedule for the evaluation of individual quality of life (SEIQoL). Int J Ment Health 1994; 23: 323.

12 Bech P, Haaber A, Joyce CRB. The Danish University Antidepressant Group (DUAG). Experiments on clinical observation and judgement in the assessment of depression: profiled videotapes and judgement analysis. Psychol Med 1986; 16: 873-883.

13 Braspenning J, Sergeant J. General practitioners' decision making for mental health problems: outcomes and ecological validity. J Clin Epidemiol 1994; 47: 1365-1372.

14 Evans JSBT, Harries C, Dennis I, Dean J. General practitioners' tacit and stated policies in the prescription of lipid lowering agents. Br J Gen Pract 1995; 45: 15-18.

15 Kee F, McDonald P, Kirwan JR, Patterson CC, Love G. The stated and tacit impact of demographic and lifestyle factors on prioritization decisions for cardiac surgery. QJM 1997; 90: 117-123.

16 Nascimento I, Nardi AE, Valenca AM, et al. Psychiatric disorders in asthmatic outpatients. Psychiatry Res 2002; 110: 73-80.
17 Policy PC. Software for judgement analysis. New York, Executive Decision Services, 1986.

18 Stewart TR. Judgment analysis: procedures. In: Human judgment. The social judgement theory view. Brehmer B, Joyce CRB, eds. Amsterdam, Elsevier, 1988; pp. 41-74.

19 Zigmond A, Snaith R. The hospital anxiety and depression scale. Acta Psychiatr Scand 1983; 67: 361-370.

20 Quanjer PH, Tammeling GJ, Cotes JE, Pedersen OF, Peslin R, Yernault J-C. Standardisation of lung function tests: official statement of the European Respiratory Society. Eur Respir J 1993; 6: Suppl. 16, 5-40.

21 Hammond KR, Adelman L. Science, values, and human judgment. Science 1976; 194: 389-396.

22 Browne JP, O’Boyle CA, McGee HM, McDonald NJ, Joyce CRB. Development of a direct weighting procedure for quality of life domains. Qual Life Res 1997; 6: 301-309.

23 Fisch HU, Hammond KR, Joyce CRB, O'Reilly M. An experimental study of the clinical judgment of general physicians in evaluating and prescribing for depression. Br J Psychiatry 1981; 138: 100-109.

24 Cooksey RW. Judgment analysis: theory, methods and applications. San Diego, Academic Press, 1996.

25 Ward JHJ. Hierarchical grouping to optimize an objective function. J Am Stat Assoc 1963; 58: 236-244.

26 Coen R, O'Mahony D, O'Boyle C, Joyce CR. Measuring the quality of life of dementia patients using the schedule for the evaluation of individual quality of life. Irish Journal of Psychology 1993; 14: 154-163.

27 Browne JP, O'Boyle CA, McGee HM, et al. Individual quality of life in the healthy elderly. Qual Life Res 1994; 3: 235-244.

28 Barley EA, Jones PW. A comparison of diary cards versus health status questionnaires as measures of the severity and impact of asthma. Eur Respir J 1999; 14: 591-596.

29 Gibson PG, Powell PG, Coughlan J, et al. Self-management education and regular practitioner review for adults with asthma (Cochrane Review). Issue 1. Chichester, John Wiley and Sons Ltd, 2004. 